\title{
Ultrasonographic Examination of Peripheral Nerves in Diabetic Peripheral Neuropathy
}

\author{
Akshay Kumar' ${ }^{1}$ Sohan Singh², Puneet Mittal ${ }^{3}$, Rishabh Yadav ${ }^{4}$ \\ ${ }^{1}$ Department of Radiodiagnosis, MMIMSR (Deemed to be University), Mullana, Ambala, Haryana, India. ${ }^{2}$ Department \\ of Radiodiagnosis, MMIMSR (Deemed to be University), Mullana, Ambala, Haryana, India. ${ }^{3}$ Department of \\ Radiodiagnosis, MMIMSR (Deemed to be University), Mullana, Ambala, Haryana, India. ${ }^{4}$ Department of \\ Radiodiagnosis, MMIMSR (Deemed to be University), Mullana, Ambala, Haryana, India.
}

\section{ABSTRACT}

\section{BACKGROUND}

Diabetes has been a major problem in India. Its slow growth is associated with many complications, most common being peripheral neuropathy. An easy and cheap investigation to diagnose the neuropathy may help in early diagnosis and decrease the economic burden on the society. The purpose of the study was to assess the usefulness of ultrasonography (USG) in the evaluation of diabetic peripheral neuropathy (DPN).

\section{METHODS}

Fifty adult diabetic patients with clinically diagnosed DPN and 50 diabetics without DPN were included in the study. USG of the medial, ulnar, and common peroneal nerves was done. The mean cross-sectional area (CSA) of the involved nerves was measured in the two groups at identical positions. The CSA was compared between the two groups, and Student t-test was applied to assess statistical significance.

\section{RESULTS}

The mean thickness of median nerve among diabetics without DPN was significantly less at $5 \mathrm{cms}$ proximal to wrist $(7.34 \pm 1.24$ vs $11.12 \pm 1.56, \mathrm{p}<0.0001)$; was significantly less at mid-forearm (6.84 \pm 0.77 vs $10.36 \pm 1.72, \mathrm{p}<0.0001)$; and was significantly less at elbow $(7.36 \pm 0.75$ vs $10.2 \pm 1.64, \mathrm{p}<0.0001)$. The mean thickness of ulnar nerve among diabetics without DPN was significantly less at wrist joint ( $6.98 \pm 0.89$ vs $8.44 \pm 1.34, \mathrm{p}<0.0001$ ); and was significantly less behind medial epicondyle $(7.44 \pm 0.93$ vs $9.36 \pm 0.98, \mathrm{p}<0.0001)$. The mean thickness of common peroneal nerve among diabetics without DPN was significantly less at neck of fibula $(7.26 \pm 1.34$ vs $9.3 \pm 1.67, \mathrm{P}<0.0001)$; and the mean thickness of posterior tibial nerve was also significantly less at $5 \mathrm{cms}$ above medial malleolus $(7.06 \pm 1.25$ vs $9.16 \pm 1.61, \mathrm{P}<0.0001$ ). There was a significant increase in the CSA of the median, ulnar, posterior tibial and common peroneal, in DPN patients as compared to diabetics without DPN $(\mathrm{p}<0.05)$.

\section{CONCLUSIONS}

USG demonstrates a morphological change in patients with DPN in the form of an increase in CSAs, which was statistically significant. USG can objectively complement other diagnostic investigations such as nerve conduction studies. High resolution ultrasonography of peripheral nerves has the potential to become the investigation of first choice for the evaluation of DPN.

\section{KEY WORDS}

Diabetes, Neuropathy, Ultrasonography, Peripheral Nerves

\author{
Corresponding Author: \\ Dr. Akshay Kumar, \\ Flat No. 21, H-Block, \\ MMU Campus, Mullana \\ Ambala-133207, Haryana, India. \\ E-mail: drakirads@gmail.com
}

DOI: $10.14260 / \mathrm{jemds} / 2020 / 245$

Financial or Other Competing Interests: None.

How to Cite This Article:

Kumar A, Singh S, Mittal $P$, et al. Ultrasonographic examination of peripheral nerves in diabetic peripheral neuropathy. J. Evolution Med. Dent. Sci. 2020;9(14):1131-1134, DOI:
Submission 02-02-2020, Peer Review 14-03-2020, Acceptance 20-03-2020, Published 06-04-2020. 


\section{BACKGROUND}

Diabetes has become one of the largest global health-care problems because of the lifestyle changes. In certain parts of the world like India, the disease has reached epidemic proportions. The disease affects almost all the organs and has complications including cardiovascular disease, nephropathy, retinopathy, and neuropathy, such as diabetic peripheral neuropathy (DPN).

The diagnosis of diabetic neuropathy is based primarily on the characteristic symptoms and is confirmed with a nerve conduction study (NCS). With advances in the ultrasound (US) technology and improvement in resolution, imaging of peripheral nerves has become feasible. Entrapment neuropathies, traumatic peripheral nerve injuries, nerve sheath tumors, etc., have been evaluated using ultrasonography (USG). Recently, there has been some interest in evaluating peripheral neuropathy in diabetics using USG. As many peripheral nerves run a superficial course, they can be easily accessible for evaluation by sonography by their predictable anatomic location and characteristic appearance. Nerves appear more echogenic than muscles and less echogenic than tendons. On a longitudinal scan, a nerve appears as multiple hypoechoic bands, corresponding to a neuronal fascicle, separated by hyperechoic lines, corresponding to the perineurium. On transverse scan, a nerve gives rise to the characteristic "honeycomb" appearance with a network of multiple rounded hypoechoic fascicle groups surrounded by hyperechoic periand epineurium. ${ }^{[1]}$

The aim of the study was to investigate the ultrasonographic features (cross-sectional area) of multiple peripheral nerves in patients with DPN at multiple sites in upper and lower extremities and to compare findings between DPN patients (test group) and diabetic without DPN (control group).

\section{METHODS}

The analytical cross-sectional study was conducted in the Department of General Medicine. Institutional ethical clearance was obtained for the study (IEC-1080) and an informed consent was taken from the patients before the study. A total of 100 subjects ( $>18$ years) were included in the study which were divided into two groups, one group as cases with 50 patients who presented with clinical features suggestive of diabetic peripheral neuropathy and 50 diabetic volunteers (controls) with no clinical evidence of peripheral neuropathy. The sample size was based on the study of Youdhwir Singh, et al[1] who observed that mean CSA of median nerve at mid-forearm in cases was $9.76 \pm 2.95 \mathrm{~mm}^{2}$ and in controls was $6.5 \pm 1.31 \mathrm{~mm}^{2}$. Taking these values as reference, the minimum required sample size with $99 \%$ power of study and $1 \%$ level of significance is 24 patients in each study group. To reduce margin of error, total sample size taken is 100 (50 patients per group)

The diagnosis of DPN was made by combination of neuropathic symptoms (sensory- numbness, burning, prickling, paraesthesia and allodynia or motor-distal muscle weakness and atrophy) and abnormal nerve conduction studies. Sonographic examination was performed with HD-15 ultrasound system (Philips ultrasound) using a 7-12 MHz linear array transducer. Any patients with $<18$ years of age, pregnant women, Person with clinical evidence of hereditary, inflammatory neuropathy, trauma etc. and cases where scanning was not possible due to poor general conditions were excluded from the study.

Cross sectional area (CSA) of the peripheral nerves including median, ulnar, posterior tibial and common peroneal nerves were measured in $\mathrm{mm}^{2}$. CSA of median nerve was calculated at $5 \mathrm{cms}$ proximal to wrist joint, mid-forearm and at elbow joint. Ulnar nerve was measured at wrist and behind medial epicondyle at the elbow, Common peroneal nerve was measured at neck of fibula and posterior tibial nerve was measured $3 \mathrm{cms}$ above medial malleolus. Echo pattern of the same nerves i.e. whether the normal fascicular pattern was seen or not was also recorded. The nerves were analyzed on color Doppler for abnormal endo-neural or perineural vascularity.

\section{Statistical Analysis}

Continuous data was written as per the requirement either in the form of its standard deviation and mean or in the form of its interquartile range and median. The distribution of the variables was tested with the Shapiro-Wilk test/ Kolmogorov-Smirnov tests of Normality. Group comparisons of values of skewed data were made with the Mann Whitney test for 2 groups. Independent t-test was done for comparison of 2 groups when data was normally distributed. (age, blood sugar levels). Categorical variables were reported as counts and percentages. Group comparisons were made with the Chi square test or Fisher's exact test. Receiver Operating Characteristic curves (ROC) were calculated to find maximal cut-off values of diabetic cases with DPN. ROC curve is plot of sensitivity versus 1 -specificity for maximal cut-off values. A P value $<0.05$ was considered significant. Analysis was done using IBM SPSS statistics (version 22.0).

\section{RESULTS}

In the present study out of the 50 diabetic patients without DPN, 37 (64\%) were males and 13 (26\%) were females. In group 1 (diabetics with DPN), 18 (36\%) were females and 32 (64\%) were males. The mean age in diabetic patients without DPN was 44 years. The youngest diabetic patient without DPN was 30 years of age and the oldest was 68 years of age. Most of the patients (42\%) with DPN were in the age group 51-60 years.

On Ultrasound we found that the mean thickness of median, ulnar and common peroneal nerve was significantly higher among the Diabetics with peripheral neuropathy $(p<0.05)$ at various levels. The mean thickness of median nerve among diabetics without DPN was significantly less at 5 cm proximal to wrist $(7.34 \pm 1.24$ vs $11.12 \pm 1.56, \mathrm{p}<0.0001)$; was significantly less at mid-forearm $(6.84 \pm 0.77$ vs $10.36 \pm$ $1.72, \mathrm{p}<0.0001)$; and was significantly less at elbow (7.36 \pm 0.75 vs $10.2 \pm 1.64, \mathrm{p}<0.0001)$. No difference in the echogenicity and vascularity was found between the two groups. (table 1). 


\begin{tabular}{|c|c|c|c|c|c|c|c|}
\hline \multirow{3}{*}{\begin{tabular}{|c|}
$\begin{array}{c}\text { Features } \\
\text { Under } \\
\text { Consideration }\end{array}$ \\
\end{tabular}} & \multirow{3}{*}{ Categories } & \multirow{2}{*}{\multicolumn{2}{|c|}{$\begin{array}{c}\text { At } 5 \mathrm{~cm} \text { Proximal to wrist } \\
(\mathrm{n}=50)\end{array}$}} & \multirow{2}{*}{\multicolumn{2}{|c|}{ At Mid-Forearm ( $\mathrm{n}=50)$}} & \multirow{2}{*}{\multicolumn{2}{|c|}{$\begin{array}{l}\text { At Elbow } \\
(n=50)\end{array}$}} \\
\hline & & & & & & & \\
\hline & & Diabetes without DPN & DPN & Diabetes without DPN & DPN & Diabetes without DPN & DPN \\
\hline \multirow{8}{*}{$\operatorname{CSA}\left(\mathrm{mm}^{2}\right)$} & $<7$ & $27(54.00 \%)$ & $0(0.00 \%)$ & $40(80.00 \%)$ & $0(0.00 \%)$ & $26(52.00 \%)$ & $1(2.00 \%)$ \\
\hline & $8-9$ & $21(42.00 \%)$ & $7(14.00 \%)$ & $10(20.00 \%)$ & $17(34.00 \%)$ & $24(48.00 \%)$ & $17(34.00 \%)$ \\
\hline & $10-12$ & $2(4.00 \%)$ & $30(60.00 \%)$ & $0(0.00 \%)$ & $28(56.00 \%)$ & $0(0.00 \%)$ & $31(62.00 \%)$ \\
\hline & $>12$ & $0(0.00 \%)$ & $13(26.00 \%)$ & $0(0.00 \%)$ & $5(10.00 \%)$ & $0(0.00 \%)$ & $1(2.00 \%)$ \\
\hline & $\mathrm{p}$ value & \multicolumn{2}{|l|}{$<.0001$} & \multicolumn{2}{|l|}{$<0001$} & \multicolumn{2}{|l|}{$<.0001$} \\
\hline & Mean \pm S.D. & $7.34 \pm 1.24$ & $11.12 \pm 1.56$ & $6.84 \pm 0.77$ & $10.36 \pm 1.72$ & $7.36 \pm 0.75$ & $10.2 \pm 1.64$ \\
\hline & Median (IQR) & $7(6-8)$ & $11(10-13)$ & $7(6-7)$ & $11(9-12)$ & $7(7-8)$ & $10.5(9-12)$ \\
\hline & $\mathrm{p}$ value & \multicolumn{2}{|l|}{$<.0001$} & \multicolumn{2}{|l|}{$<.0001$} & \multicolumn{2}{|l|}{$<.0001$} \\
\hline \multirow{3}{*}{ Echogenicity } & Normal & $50(100.00 \%)$ & $50(100.00 \%)$ & $50(100.00 \%)$ & $50(100.00 \%)$ & $50(100.00 \%)$ & $50(100.00 \%)$ \\
\hline & Abnormal & $0(0.00 \%)$ & $0(0.00 \%)$ & $0(0.00 \%)$ & $0(0.00 \%)$ & $0(0.00 \%)$ & $0(0.00 \%)$ \\
\hline & $\mathrm{p}$ value & & & \multicolumn{2}{|l|}{ - } & \multicolumn{2}{|l|}{ - } \\
\hline \multirow{3}{*}{ Vascularity } & Normal & $50(100.00 \%)$ & $50(100.00 \%)$ & $50(100.00 \%)$ & $50(100.00 \%)$ & $50(100.00 \%)$ & $50(100.00 \%)$ \\
\hline & Abnormal & $0(0.00 \%)$ & $0(0.00 \%)$ & $0(0.00 \%)$ & $0(0.00 \%)$ & $0(0.00 \%)$ & $0(0.00 \%)$ \\
\hline & $\mathrm{p}$ value & \multicolumn{2}{|r|}{ 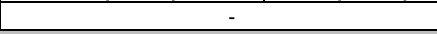 } & \multirow{2}{*}{\multicolumn{2}{|c|}{ 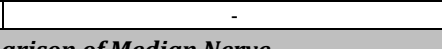 }} & \multicolumn{2}{|l|}{-} \\
\hline \multicolumn{7}{|c|}{ Table 1. Comparison of Median Nerve } & \\
\hline
\end{tabular}

\begin{tabular}{|c|c|c|c|c|c|}
\hline \multirow{2}{*}{$\begin{array}{c}\text { Features } \\
\text { Under } \\
\text { Consideration }\end{array}$} & \multirow{2}{*}{ Categories } & \multicolumn{2}{|c|}{$\begin{array}{l}\text { At Wrist Joint } \\
\qquad(n=50)\end{array}$} & \multicolumn{2}{|c|}{$\begin{array}{c}\text { Behind Medial } \\
\text { Epicondyle }(\mathrm{N}=50)\end{array}$} \\
\hline & & $\begin{array}{c}\text { Diabetes } \\
\text { without } \\
\text { DPN }\end{array}$ & DPN & $\begin{array}{c}\text { Diabetes } \\
\text { without } \\
\text { DPN }\end{array}$ & DPN \\
\hline \multirow{8}{*}{ 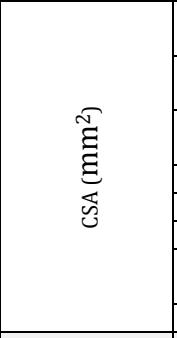 } & $<7$ & $\begin{array}{c}35 \\
(70.00 \%) \\
\end{array}$ & \begin{tabular}{|c|}
14 \\
$(28.00 \%)$
\end{tabular} & $\begin{array}{c}24 \\
(48.00 \%) \\
\end{array}$ & $\begin{array}{c}2 \\
(4.00 \%) \\
\end{array}$ \\
\hline & 8-9 & $\begin{array}{c}15 \\
(30.00 \%) \\
\end{array}$ & $\begin{array}{c}24 \\
(48.00 \%) \\
\end{array}$ & $\begin{array}{c}26 \\
(52.00 \%) \\
\end{array}$ & \begin{tabular}{|c|}
24 \\
$(48.00 \%)$ \\
\end{tabular} \\
\hline & $10-12$ & $\begin{array}{c}0 \\
(0.00 \%) \\
\end{array}$ & $\begin{array}{c}12 \\
(24.00 \%)\end{array}$ & $\begin{array}{c}0 \\
(0.00 \%) \\
\end{array}$ & $\begin{array}{c}24 \\
(48.00 \%)\end{array}$ \\
\hline & $>12$ & $0(0.00 \%)$ & $0(0.00 \%)$ & $0(0.00 \%)$ & $0(0.00 \%)$ \\
\hline & $\mathrm{p}$ value & \multicolumn{2}{|c|}{$<.0001$} & \multicolumn{2}{|c|}{$<.0001$} \\
\hline & Mean \pm S.D. & $6.98 \pm 0.89$ & $8.44 \pm 1.34$ & \multicolumn{2}{|c|}{\begin{tabular}{l|l}
$7.44 \pm 0.93$ & $9.36 \pm 0.98$ \\
\end{tabular}} \\
\hline & $\begin{array}{c}\text { Median } \\
\text { (IQR) } \\
\end{array}$ & $7(6-8)$ & $9(7-9)$ & $8(7-8)$ & $9(9-10)$ \\
\hline & $\mathrm{p}$ value & \multicolumn{2}{|c|}{$<.0001$} & \multicolumn{2}{|c|}{$<.0001$} \\
\hline \multirow{3}{*}{ 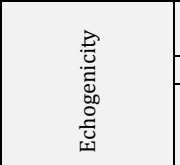 } & Normal & $\begin{array}{c}50 \\
(100.00 \%)\end{array}$ & $\begin{array}{c}50 \\
(100.00 \%) \\
\end{array}$ & $\begin{array}{c}50 \\
(100.00 \%)\end{array}$ & \begin{tabular}{|c|}
50 \\
$(100.00 \%)$
\end{tabular} \\
\hline & Abnormal & $0(0.00 \%)$ & $0(0.00 \%)$ & $0(0.00 \%)$ & $0(0.00 \%)$ \\
\hline & $\mathrm{p}$ value & & & & \\
\hline \multirow{3}{*}{ 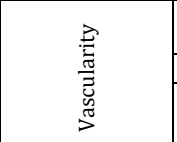 } & Normal & $\begin{array}{c}50 \\
(100.00 \%) \\
\end{array}$ & $\begin{array}{c}50 \\
(100.00 \%) \\
\end{array}$ & $\begin{array}{c}50 \\
(100.00 \%) \\
\end{array}$ & \begin{tabular}{|c|}
50 \\
$(100.00 \%)$ \\
\end{tabular} \\
\hline & Abnormal & $0(0.00 \%)$ & $0(0.00 \%)$ & $0(0.00 \%)$ & $0(0.00 \%)$ \\
\hline & $\mathrm{p}$ value & - & & & \\
\hline \multicolumn{6}{|c|}{ Table 2. Comparison of Ulnar Nerve } \\
\hline
\end{tabular}

\begin{tabular}{|c|c|c|c|}
\hline \multirow{2}{*}{$\begin{array}{c}\text { Features } \\
\text { Under } \\
\text { Consideration }\end{array}$} & \multirow{2}{*}{ Categories } & \multicolumn{2}{|c|}{ At Neck of Fibula $(n=50)$} \\
\hline & & Diabetes without DPN & DPN \\
\hline \multirow{7}{*}{$\operatorname{CSA}\left(\mathrm{mm}^{2}\right)$} & $<7$ & $30(60.00 \%)$ & $5(10.00 \%)$ \\
\hline & 8-9 & $18(36.00 \%)$ & $30(60.00 \%)$ \\
\hline & $10-11$ & $2(4.00 \%)$ & $15(30.00 \%)$ \\
\hline & $>12$ & $0(0.00 \%)$ & $0(0.00 \%)$ \\
\hline & $\mathrm{p}$ value & \multicolumn{2}{|l|}{$<.0001$} \\
\hline & Mean \pm S.D. & $7.26 \pm 1.34$ & $9.3 \pm 1.67$ \\
\hline & $\begin{array}{l}\text { Median(IQR) } \\
\text { p value }\end{array}$ & \multicolumn{2}{|l|}{$<.0001$} \\
\hline \multirow[b]{2}{*}{ Echogenicity } & Normal & 49 (98.00\%) & $50(100.00 \%)$ \\
\hline & $\begin{array}{c}\text { Abnormal } \\
\text { p value }\end{array}$ & \multicolumn{2}{|l|}{$1(2.00 \%)$} \\
\hline \multirow[b]{2}{*}{ Vascularity } & & $50(100.00 \%)$ & $50(100.00 \%)$ \\
\hline & $\begin{array}{l}\text { Abnormal } \\
\text { p value }\end{array}$ & \\
\hline$T a$ & Compariso & fCommon Peroneal Ne & \\
\hline
\end{tabular}

The mean thickness of ulnar nerve among diabetics without DPN was significantly less at wrist joint (6.98 \pm 0.89 vs $8.44 \pm 1.34, \mathrm{p}<0.0001$ ); and was significantly less behind medial epicondyle $(7.44 \pm 0.93$ vs $9.36 \pm 0.98, p<0.0001)$. No difference in the echogenicity and vascularity was found between the two groups. (table 2) The mean thickness of common peroneal nerve among diabetics without DPN was significantly less at neck of fibula $(7.26 \pm 1.34$ vs $9.3 \pm 1.67$, $\mathrm{p}<0.0001$ ); (table 3) and the mean thickness of posterior tibial nerve was also significantly less at $5 \mathrm{~cm}$ above medial malleolus among the patients without DPN $(7.06 \pm 1.25$ vs $9.16 \pm 1.61, p<0.0001$ ). No difference in the echogenicity and vascularity was found between the two groups. (table 4).

\begin{tabular}{|c|c|c|c|}
\hline \multirow{2}{*}{$\begin{array}{l}\text { Features Under } \\
\text { Consideration }\end{array}$} & \multirow[t]{2}{*}{ Categories } & \multicolumn{2}{|c|}{$\begin{array}{l}5 \mathrm{cms} \text { Above Medial Malleolus } \\
\qquad(\mathrm{n}=50)\end{array}$} \\
\hline & & Diabetes without DPN & DPN \\
\hline \multirow{7}{*}{$\operatorname{CSA}\left(\mathrm{mm}^{2}\right)$} & $<7$ & $37(74.00 \%)$ & $10(20.00 \%)$ \\
\hline & $8-9$ & $11(22.00 \%)$ & $12(24.00 \%)$ \\
\hline & $10-11$ & $2(4.00 \%)$ & $28(56.00 \%)$ \\
\hline & $>12$ & $0(0.00 \%)$ & $0(0.00 \%)$ \\
\hline & pvalue & \multicolumn{2}{|l|}{$<0.0001$} \\
\hline & Mean \pm S.D. & $7.06 \pm 1.25$ & $9.16 \pm 1.61$ \\
\hline & $\begin{array}{l}\text { Median(IQR) } \\
\text { p value }\end{array}$ & \multicolumn{2}{|l|}{$<.0001$} \\
\hline \multirow[b]{2}{*}{ Echogenicity } & Normal & \multirow{2}{*}{$\begin{array}{l}49(98.00 \%) \\
1(2.00 \%)\end{array}$} & $50(100.00 \%)$ \\
\hline & $\begin{array}{l}\text { Abnormal } \\
\text { p value }\end{array}$ & & $0(0.00 \%)$ \\
\hline \multirow{2}{*}{ Vascularity } & & \multirow{2}{*}{$\begin{array}{c}50(100.00 \%) \\
0(0.00 \%)\end{array}$} & $50(100.00 \%)$ \\
\hline & $\begin{array}{l}\text { Abnormal } \\
\text { p value }\end{array}$ & & $0(0.00 \%)$ \\
\hline & Compariso & f Posterior Tibial Nerv & \\
\hline
\end{tabular}

\section{DISCUSSION}

Diabetes is a common problem in the world affecting almost all the organs. Although diabetic neuropathy is not lifethreatening, it can be extremely debilitating for the patient. The diagnosis of diabetic neuropathy is based primarily on characteristic symptoms and is confirmed with an NCS. USG of the peripheral nerves is a recent development in neurology. With advances in US transducer technology and improvement in the resolution routine, the use of ultrasound for nerve imaging has become possible. Peripheral nerves run superficially in many cases, and they can be evaluated using USG. Further, because of their characteristic fascicular pattern, even very small nerves can be studied. On USG, nerves are more echogenic than muscles but less echogenic than tendons and are less mobile than tendons. High resolution sonography was able to demonstrate median, ulnar, posterior tibial, and CPNs in all the healthy volunteers and patients examined in our study.[2]

The mean CSA of the median nerve in our study was significantly higher $(p<0.0001)$ at all three levels of examination in patients with DPN than those without DPN. Our findings were in concordance with those of Watanabe $\mathrm{T}$ et al.,[3] who found that there is a significant increase in the 
CSA of the median nerve in patients with DPN as compared with the controls. The mean CSA (in $\mathrm{mm}^{2}$ ) of the median nerve in patients vs. healthy volunteers was $13.5 \pm 2.8$ vs. $9 \pm$ $2,9.1 \pm 2.7$ vs. $7.1 \pm 1.6$, and $7.2 \pm 2.6$ vs. $7.4 \pm 3.2$ at the carpal tunnel, $5 \mathrm{~cm}$ proximal to the wrist crease and at the elbow joint, respectively. The mean CSA of the median nerve in Singh Y et al[1] study was also significantly higher ( $p<$ 0.0001 ) at all three levels of examination in patients with DPN than the healthy volunteers i.e., $11.61 \pm 2.87$ vs. $7.09 \pm$ 1.49 at $5 \mathrm{~cm}$ proximal to the wrist crease, $9.76 \pm 2.95$ vs. $6.5 \pm$ 1.31 at the level of mid-forearm, and $10.50 \pm 2.27$ vs. $6.90 \pm$ 1.43 at the elbow joint. Pitarokoili et al.,[4] also found an increased mean CSA (in $\mathrm{mm}^{2}$ ) of the median nerve in patients as compared to controls, i.e., $11.21 \pm 2.1$ vs. $9.0 \pm 1.58$ at the carpal tunnel and $7.92 \pm 2.14$ vs. $6.6 \pm 1.6$ at mid-forearm. Similar findings have been reported by Afsal $\mathrm{M}$ et al., [5] who found that on high-resolution sonography, there was a diffuse thickening of the peripheral nerve in these patients, and the mean CSA of the median nerve and ulnar nerve was found to be significantly higher in patients with DPN than the normal matched controls. The mean CSA of the median nerve of patients with DPN was $10.5 \mathrm{~mm}^{2}$ at the carpal tunnel, and $8.69 \mathrm{~mm}^{2}$ in the forearm $10 \mathrm{~cm}$ proximal to the wrist, whereas the CSA was $7.1 \mathrm{~mm}^{2}$ and $5.89 \mathrm{~mm}^{2}$, respectively at the same levels in controls.

The CSA of the ulnar nerve was significantly higher ( $\mathrm{p}<$ 0.0001) at both the levels in DPN patients than those without DPN. Our findings were in concordance with that of Pitarokoili et al., [4] who found that there was a significant increase in the CSA of the ulnar nerve (in $\mathrm{mm}^{2}$ ), and it was greater in patients with DPN than in the controls, i.e., $6.30 \pm$ 1.92 vs. $5.0 \pm 0.94$ at the Guyon's canal and $8.34 \pm 2.46$ vs. $5.99 \pm 1.57$ behind the medial epicondyle. Similar findings were recorded by Afsal M et al. [5] Even in the study by Singh $\mathrm{Y}$ et al, the CSA of the ulnar nerve was significantly higher ( $\mathrm{p}$ $<0.0001$ ) at both the levels in DPN patients than in the healthy volunteers, i.e., $7.22 \pm 1.66$ vs. $5.56 \pm 1.22$ at the wrist joint, and $10.33 \pm 3.45$ vs. $6.50 \pm 1.41$ behind the medial epicondyle. The mean CSA of CPN at the neck of the fibula was significantly higher ( $p$ value $<0.0001$ ) in DPN patients than those without DPN. In the study by Singh Y et al,[1] the mean CSA of CPN at the neck of the fibula was significantly higher ( $\mathrm{p}$ value $<0.0001$ ) in DPN patients than in healthy volunteers i.e., $11.38 \pm 4.93$ vs $6.75 \pm 1.4$. In majority of the patients with DPN, i.e., $28 / 37$ (75.68\%), the mean CSA of the CPN was $>9$ at the neck of fibula and was between $9-12$ in $43.24 \%$ of patients; and, in majority of the healthy volunteers i.e., $62.22 \%$, the CPN mean CSA was between $6-9$, and it was $<9$ in $93.33 \%$ healthy volunteers. The study by Pitarokoili et al., [4] also showed similar results where the mean CSA (in $\mathrm{mm}^{2}$ ) of the fibular nerve at the fibular head was greater in patients than in the controls (i.e., $12.22 \pm 4.97$ vs. $7.2 \pm 1.89$ ). The correlation of USG findings with NCS was not possible because this nerve is not routinely evaluated by NCS.

The mean thickness of posterior tibial nerve was also significantly less at $5 \mathrm{~cm}$ above medial malleolus among the patients without DPN (7.06 \pm 1.25 vs $9.16 \pm 1.61$, p<0.0001). In the study by Singh Y et al,[1] the CSA of the posterior tibial nerve was significantly higher $(p<0.0001)$ at $3 \mathrm{~cm}$ above the medial malleolus than that seen in the healthy volunteers $(7.99 \pm 2.15$ vs. $5.97 \pm 1.83)$. The CSA of the posterior tibial nerve was $<7$ in most of the healthy volunteers, whereas in the majority of patients with DPN, it was $>7$. Our finding was concordant with the findings of Watanabe et al. [3] Similar findings were reported by Riazi S et al.,[6] Pitarokoili et al,[4] that the mean CSA of the posterior tibial nerve (P TN) was larger in patients with DPN than in control subjects. Thus, enlargement of nerve size, as measured by CSA, was a common finding in all diabetic patients with neuropathy. The CSA of nerves, such as median, ulnar, posterior tibial, and common peroneal, varied with the severity of neuropathy, which was statistically significant.

The limitations of the study were that the follow -up sugar levels and glycosylated hemoglobin levels of the patients were not done. Secondly, the treatment protocol was not compared with the USG findings. However, based on the study results we recommend future studies to validate USG as a novel modality to screen and diagnose the early cases of diabetic neuropathy that may help in better management of the patients.

\section{CONCLUSIONS}

The study shows the utility of USG in demonstrating changes of DPN in a large number of upper and lower limb nerves. Thus, it has the potential to allow for a non-invasive evaluation of DPN. USG demonstrates a morphological change in patients with DPN in the form of an increase in CSAs, which was statistically significant. USG can objectively complement other diagnostic investigations such as nerve conduction studies. High resolution ultrasonography of peripheral nerves has the potential to become the investigation of first choice for the evaluation of DPN.

\section{REFERENCES}

[1] Singh Y, Dixit R, Singh S, et al. High resolution ultrasonography of peripheral nerves in diabetic peripheral neuropathy. Neurol India 2019;67(Suppl 7):S71-S6.

[2] Silvestri E, Martinoli C, Derchi LE, et al. Echotexture of peripheral nerves: correlation between US and histologic findings and criteria to differentiate tendons. Radiology 1995;197(1):291-6.

[3] Watanabe $T$, Ito $H$, Sekine A, et al. Sonographic evaluation of the peripheral nerve in diabetic patients: the relationship between nerve conduction studies, echo intensity, and cross-sectional area. J Ultrasound Med 2010;29(5):697-708.

[4] Pitarokoili K, Kerasnoudis A, Behrendt V, et al. Facing the diagnostic challenge: nerve ultrasound in diabetic patients with neuropathic symptoms. Muscle Nerve 2016;54(1):18-24.

[5] Afsal M, Chowdhury V, Prakash A, et al. Evaluation of peripheral nerve lesions with high-resolution ultrasonography and color Doppler. Neurol India 2016;64(5):1002-9.

[6] Riazi S, Bril V, Perkins BA, et al. Can ultrasound of the tibial nerve detect diabetic peripheral neuropathy? A cross-sectional study. Diabetes Care 2012;35(12):25759. 